\title{
Synthetic Access to a Hydrocarbon-Soluble Trifluorinated Ge(II) Compound and its Sn(II) Congener
}

\author{
Prinson P. Samuel, ${ }^{\dagger}$ Yan Li, ${ }^{\ddagger}$ Herbert W. Roesky, ${ }^{* \dagger}$ Veniamin Chevelkov, $^{\S}$ Adam Lange, ${ }^{\S}$ \\ Anja Burkhardt," and Birger Dittrich* ${ }^{*}$, \\ ${ }^{\dagger}$ Institut für Anorganische Chemie, Georg-August-Universität, Tammannstrasse 4, D-37077, Göttingen, Germany \\ ${ }^{\ddagger}$ State Key Laboratory of Physical Chemistry of Solid Surfaces, College of Chemistry and Chemical Engineering, Xiamen University, \\ Xiamen, Fujian, 361005, China \\ ${ }^{\S}$ Research Group Solid-State NMR Spectroscopy, Max Planck Institute for Biophysical Chemistry, Am Fassberg 11, D-37077, \\ Göttingen, Germany \\ "Deutsches Elektronen-Synchrotron, Notkestrasse 85, D-22607, Hamburg, Germany \\ ${ }^{\perp}$ Institut für Anorganische und Angewandte Chemie, Universität Hamburg, Martin-Luther-King-Platz 6, D-20146, Hamburg, \\ Germany
}

Supporting Information

ABSTRACT: Trifluorinated germanium anions attracted attention of theoretical chemists already in the late 1990s to predict their physical and chemical properties. However these species were not synthesized in the laboratory, although substantial evidence for their existence was obtained from the mass spectrometry of $\mathrm{GeF}_{4}$. The present study shows that controlled fluorination of $\mathrm{LMNMe}_{2}\left(\mathrm{~L}=\mathrm{PhC}\left(\mathrm{N}^{t} \mathrm{Bu}\right)_{2}, \mathrm{M}=\mathrm{Ge}, \mathrm{Sn}\right)$ using HF. pyridine in toluene leads to the formation of $\left[\mathrm{LH}_{2}\right]^{+}\left[\mathrm{MF}_{3}\right]^{-}$under elimination of $\mathrm{HNMe}_{2}$. The products contain the trifluorinated $\mathrm{Ge}$ (II) and $\mathrm{Sn}$ (II) anionic species which are stabilized by interionic $\mathrm{H} \cdots \mathrm{F}$ bonds. The new compounds were characterized by single crystal X-ray structural analysis, NMR spectroscopy, and elemental analysis.

$\mathrm{O}$ ne of the widely studied class of compounds in chemistry consists of silylenes, germylenes, and stanylenes which are in fact heavier carbene analogues of silicon, germanium, and tin, respectively. Silicon, germanium, and tin centers in these compounds exhibit an oxidation state of +2 . A number of room temperature stable silylenes, ${ }^{1 \mathrm{a}-\mathrm{g}}$ germylenes, ${ }^{1 \mathrm{~h}, \mathrm{i}-\mathrm{n}}$ and stanylenes $^{1 \mathrm{i}, \mathrm{o}}$ are known, and the advent of these compounds opened a fertile research field of group 14 chemistry. Much effort has been devoted to the synthesis of compounds with low-valent centers bearing hydrides, hydroxyl groups, or halides. Among them the fluorides of group 14 elements are important due to their synthetic utility in the laboratory as well as in industry. ${ }^{2}$ In the literature, the known group 14 fluoro compounds are preferentially in the +4 oxidation state. Only a few examples of organo germanium(II) and tin(II) fluorides are known. ${ }^{3,4}$ In two recent communications we reported on the synthesis of lead(II)monofluoride 5 from dimethylamino lead(II) and tin(II)monofluoride ${ }^{4 \mathrm{~d}}$ from dimethylamino tin(II) using pentafluoropyridine as a fluorinating reagent. A similar reaction using diisopropylamino germanium(II) however led to the oxidative addition of a $\mathrm{C}-\mathrm{F}$ bond of pentafluoropyridine at the $\mathrm{Ge}(\mathrm{II})$ center. $^{4 d}$ In this respect our continuous interest in the chemistry of fluorides of low-valent group 14 elements prompted us to utilize dimethyl amino $\mathrm{Ge}(\mathrm{II})$ and $\mathrm{Sn}$ (II) compounds to access the trifluorinated anions of these elements in the +2 oxidation state.

The behavior of different coordinate germanium fluorides has been experimentally and theoretically studied by many chemists. The broad interest in such compounds is mainly due to their utility in the fine processing of semiconductors. Even though the structure of $\mathrm{GeF}_{3}$ is still unknown, geometries of $\mathrm{GeF}, \mathrm{GeF}_{2}$, and $\mathrm{GeF}_{4}$ in their ground states have been studied by experimental methods. ${ }^{6}$ However, the experimental data revealing the properties or structures of $\mathrm{GeF}_{n}{ }^{-}$species are scarce in the literature even though such ions had been detected in the mass spectrum of $\mathrm{GeF}_{4}$ already in $1972 .^{7}$ In this context, theoretical chemists were interested in finding the optimized structures of such monoanionic species since 1990s. ${ }^{8}$ Very recently, Bjarnason et al. described the dissociative electron attachment to $\mathrm{GeF}_{4}$ in which the molecular ion $\mathrm{GeF}_{4}^{-}$and the fragments $\mathrm{GeF}_{3}^{-}, \mathrm{GeF}_{2}^{-}, \mathrm{GeF}^{-}$, and $\mathrm{F}^{-}$were observed with appreciable intensities. ${ }^{9}$ However, no synthetic route has been outlined so far for obtaining stable complexes with $\mathrm{GeF}_{3}{ }^{-}$anions, and the synthetic methodology described in this communication fills that niche. In contrast to this, several compounds with $\mathrm{SnF}_{3}^{-}$anions are known including the inorganic salts like $\mathrm{KSnF}_{3}$ and $\mathrm{NH}_{4} \mathrm{SnF}_{3}$ and complex inorganic structures like $\left[\mathrm{Ni}\left(\mathrm{H}_{2} \mathrm{O}\right)_{6}\right]\left(\mathrm{SnF}_{3}\right)_{2}{ }^{10 a-e}$ The disadvantage of these salts is their insolubility in organic solvents. In addition, compounds like (naphthalene-1,5-diammonim) $\left(\mathrm{SnF}_{3}\right)_{2}$ are also known for which the cationic part is organic. ${ }^{10 \mathrm{f}, \mathrm{g}}$

Our initial attempts to prepare $\mathrm{GeF}_{3}{ }^{-}$and $\mathrm{SnF}_{3}{ }^{-}$anionic species by the fluorination of $\mathrm{GeCl}_{3}{ }^{-}$and $\mathrm{SnCl}_{3}{ }^{-}$anions present in our previously reported $[(\mathrm{LB}) \mathrm{MCl}]\left[\mathrm{MCl}_{3}\right]$ complexes $^{11}$ (LB $=$ 2,6-diacetylpyridinebis(2,6-diisopropylanil), $\mathrm{M}$ $=\mathrm{Ge}, \mathrm{Sn})$ were not successful. Inspired by our recent success in using dimethylamino lead(II) and tin(II) as precursors for

Received: November 28, 2013

Published: January 7, 2014 
obtaining the corresponding monofluorides, we used $\mathrm{LGeNMe}_{2}$ (1) and $\mathrm{LSnNMe}_{2}$ (2) as starting materials for $\mathrm{GeF}_{3}^{-}$and $\mathrm{SnF}_{3}{ }^{-}$anions, respectively. In a controlled reaction with HF. pyridine, 1 and 2 afford $\left(\mathrm{LH}_{2}\right)^{+}\left(\mathrm{GeF}_{3}\right)^{-}$(3) and $\left(\mathrm{LH}_{2}\right)^{+}\left(\mathrm{SnF}_{3}\right)^{-}(4)$ in good yields.

To a precooled solution $\left(-78^{\circ} \mathrm{C}\right)$ of $1(2), 3$ equiv of HF. pyridine were added very slowly under strict inert atmosphere, and the stirring was continued for $30 \mathrm{~min}$ allowing the temperature to rise gradually. One proton of HF reacts with $\mathrm{NMe}_{2}$ to form $\mathrm{HNMe}_{2}$. The remaining two protons react with the anionic amidinate $\left(\mathrm{L}^{-}\right)$ligand to form the $\mathrm{LH}_{2}{ }^{+}$species, the cation of 3 (4). The 3 equiv of fluoride ions react with the $\mathrm{M}(\mathrm{II})$ center $(\mathrm{M}=\mathrm{Ge}, \mathrm{Sn})$ to form the $\mathrm{MF}_{3}{ }^{-}$species, the anion of 3 (4). (Scheme 1).

\section{Scheme 1. Syntheses of Compounds 3 and 4}

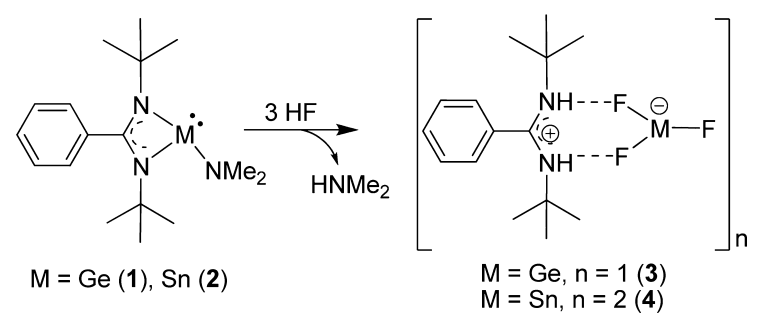

Single crystals of $\mathbf{3}$ and $\mathbf{4}$ suitable for X-ray diffraction were obtained from their toluene solutions. Compound 3 crystallizes in the orthorhombic space group $P 2_{1} 2_{1} 2_{1}$. The molecular structure of 3 shows that $\mathrm{GeF}_{3}$ has a trigonal pyramidal structure with the $\mathrm{F}$ atoms at the base and $\mathrm{Ge}$ atom at the apex (Figure 1). Two of the three $\mathrm{F}$ atoms of $\mathrm{GeF}_{3}{ }^{-}$interact with the

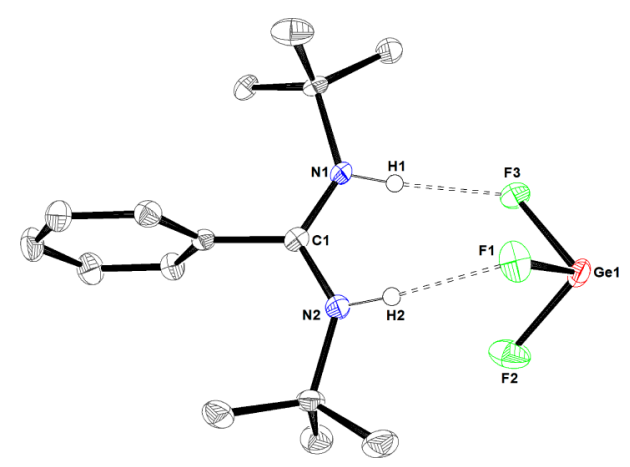

Figure 1. Molecular structure of 3. Hydrogen atoms (except of NH) are omitted for clarity. Anisotropic displacement parameters are depicted at the $50 \%$ probability level. Selected bond lengths $[\AA]$ and bond angles $\left[^{\circ}\right]$ : $\mathrm{C} 1-\mathrm{N} 1,1.325(3) ; \mathrm{C} 1-\mathrm{N} 2,1.322(3) ; \mathrm{Ge} 1-\mathrm{F} 1$, 1.825(2); Ge1-F2, 1.800(2); Ge1-F3, 1.796(2); N1-C1-N2, 118.2(2), F1-Ge1-F2, 90.31(10), F1-Ge1-F3, 90.10(12), F2Ge1-F3, 91.07(11).

$\mathrm{H}$ atoms of the $\mathrm{NH}$ groups present in the cationic part. The average $\mathrm{F}-\mathrm{Ge}-\mathrm{F}$ bond angle is $90.49^{\circ}$ which is significantly smaller than the standard tetrahedral angle $\left(109^{\circ} 28^{\prime}\right)$, and this is attributed to the large repulsion experienced by the $\mathrm{Ge}-\mathrm{F}$ bond pairs from the lone pair present in the germanium atom. Moreover, the $\mathrm{H} \cdots \mathrm{F}$ interactions associated with two fluorine atoms also play a significant role in the size of the bond angle. The $\mathrm{F}-\mathrm{Ge}-\mathrm{F}$ bond angle (av 90.49 ${ }^{\circ}$ ) experimentally found in the present study is close to the corresponding value predicted at different levels of theory (95.1 ${ }^{\circ} \mathrm{BHLYP}, 95.7^{\circ} \mathrm{B} 3 \mathrm{LYP}, 96.2^{\circ}$
BP86, 96.4 BLYP) by Schaefer et al. ${ }^{\circ}$ The average Ge-F bond distance is $1.807 \AA$. The $\mathrm{C}-\mathrm{N}$ bond distances are $1.325(3)$ and 1.322(3) $\AA$ which lie in between single- and double-bond distances, indicating the delocalization of the positive charge between the two nitrogen atoms.

Compound 4 crystallizes in the monoclinic space group $P 2_{1} /$ c. 4 is not isostructural with 3 as the former shows a dimeric arrangement in the crystal structure (Figure 2). Two Sn atoms

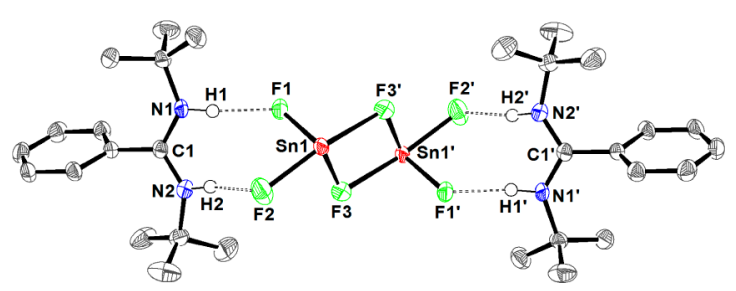

Figure 2. Dimeric molecular structure of 4 . Hydrogen atoms (except of $\mathrm{NH}$ ) are omitted for clarity. Anisotropic displacement parameters are depicted at the $50 \%$ probability level. Selected bond lengths $[\AA]$ and bond angles $\left[{ }^{\circ}\right]$ : $\mathrm{C} 1-\mathrm{N} 1,1.323(3) ; \mathrm{C} 1-\mathrm{N} 2,1.319(4)$; Sn1-F1, 2.017(3); Sn1-F2, 2.035(3); Sn1-F3, 2.043(5); $\mathrm{Sn}_{1}-\mathrm{F}_{3}{ }^{\prime}, 2.217$; N1C1-N2, 117.6(2), F1-Sn1-F2, 84.61(11), F1-Sn1-F3, 90.89(18), F2-Sn1-F3, 85.12(16); F3-Sn1-F3', 69.96(17); Sn1-F3-Sn1', $110.04(17)$.

are bridged through two fluorine atoms of the $\mathrm{SnF}_{3}{ }^{-}$units, and the remaining fluorine atoms are connected to the $\mathrm{NH}$ groups of the corresponding cationic ligands through hydrogen bonds. The $\mathrm{SnF}_{3}{ }^{-}$anions present in the dimer represent two trigonal pyramids with fluorine atoms constituting the bases and $\mathrm{Sn}$ atoms occupying the apex positions. The arrangements of the two units are in such a way that the vectors passing through the centers of the triangular bases to the corresponding apexes are parallel but in opposite directions. The $\mathrm{Sn}-\mathrm{F}$ bond distances are 2.017(3) (Sn1-F1), 2.035(3) (Sn1-F2), and 2.043(5) (Sn1-F3). The Sn1-F3' bond distance is $2.217 \AA$, which is longer than the Sn1-F3 bond length $(2.043(5) \AA)$. This indicates that the bridging fluorine atoms are not equally arranged between the two tin atoms and the tin-fluorine core structure can be better regarded as $\left[\left(\mathrm{SnF}_{3}\right)^{-}\right]_{2}$ rather than $\mathrm{Sn}_{2} \mathrm{~F}_{6}{ }^{2-}$. The Sn1F3Sn1'F3' core constitutes a parallelogram with the angles $69.96(17)^{\circ}\left(\mathrm{F} 3-\mathrm{Sn} 1-\mathrm{F} 3^{\prime}\right)$ and $110.04(17)^{\circ}$ $\left(\mathrm{Sn} 1-\mathrm{F} 3-\mathrm{Sn} 1^{\prime}\right)$, the center of which acts as an inversion center in the dimeric structure, $\left[\left(\mathrm{LH}_{2}\right)^{+}\left(\mathrm{SnF}_{3}\right)^{-}\right]_{2}$.

The $\mathrm{NH}$ protons in the cation of 3 show the resonance at $9.22 \mathrm{ppm}$ in the ${ }^{1} \mathrm{H}$ NMR spectrum. The ${ }^{19} \mathrm{~F}$ NMR spectrum exhibits a single resonance at $-62.98 \mathrm{ppm}$ corresponding to the three fluorine atoms in the $\mathrm{GeF}_{3}{ }^{-}$anion. A difference between the hydrogen-bonded fluorine atoms and the terminal fluorine atom was not observed in the NMR spectrum probably due to the fast exchange of the fluorine atoms. This shows that the hydrogen bonds involving the $\mathrm{NH}$ and $\mathrm{F}$ atoms are very weak and thereby allow the $\mathrm{GeF}_{3}^{-}$unit to rapidly exchange the positions of the fluorine atoms. The ${ }^{1} \mathrm{H}$ NMR spectrum of 4 shows the $\mathrm{NH}$ resonance at $9.81 \mathrm{ppm}$. The corresponding ${ }^{19} \mathrm{~F}$ NMR spectrum in solution exhibits the resonance at -81.41 ppm. The ${ }^{119} \mathrm{Sn}$ NMR spectrum shows a broad resonance at $-531.67 \mathrm{ppm}$. The $\mathrm{Sn}-\mathrm{F}$ coupling was not observed at room temperature, but in the ${ }^{19} \mathrm{~F}$ NMR spectrum measured at -80 ${ }^{\circ} \mathrm{C}$, the fluorine resonance is flanked by two ${ }^{119} \mathrm{Sn}$ satellites with a coupling constant of $J\left({ }^{119} \mathrm{Sn}-{ }^{19} \mathrm{~F}\right)=2959 \mathrm{~Hz}$.

Even though several compounds containing $\mathrm{SnF}_{3}{ }^{-}$anions are known so far, ${ }^{10}$ NMR spectra of these compounds were seldom 
reported. The main obstacle for utilizing NMR spectroscopy for the characterization of trifluorinated stannate compounds is their limited solubility in common organic solvents. However, the ${ }^{19} \mathrm{~F}$ NMR spectrum of 4 shows a relatively broad $(105 \mathrm{~Hz}$ half width) single resonance, and the fluorine atoms involved in the $\mathrm{H} \cdots \mathrm{F}$ and $\mathrm{Sn} \cdots \mathrm{F}$ contacts were not differentiable. Nevertheless, at $-60{ }^{\circ} \mathrm{C}$ the chemical shift position slightly shifts to $-82.20 \mathrm{ppm}$ with a half width of $210 \mathrm{~Hz}$. However, recording the ${ }^{19} \mathrm{~F}$ NMR spectrum of 3 at $-60{ }^{\circ} \mathrm{C}$ also did not result in the splitting of the peak except that the chemical shift position was slightly shifted from $-62.98 \mathrm{ppm}\left(25^{\circ} \mathrm{C}\right)$ to $-63.27 \mathrm{ppm}\left(-60{ }^{\circ} \mathrm{C}\right)$. It should be noted that the ${ }^{19} \mathrm{~F}$ NMR spectra not reflecting the nonequivalent fluorine atoms as evident from the molecular structures have been reported for other fluorides too. For example, the ${ }^{19} \mathrm{~F}$ NMR spectrum of $\left[\mathrm{SbF}_{3}(\text { phen })\right]_{2}$ (phen = 1,10-phenanthroline) shows only one resonance at $-95.8 \mathrm{ppm}\left(-83^{\circ} \mathrm{C}\right)$ even though the molecular structure of this compound is a dimer with four terminal and two bridging fluorine atoms. ${ }^{12}$ The ${ }^{19} \mathrm{~F}$ NMR of the tin fluorides recently reported by Gurnani et al. and others also exhibited a smaller number of fluorine resonances in the NMR spectra than the number of nonequivalent fluorine atoms found in the molecular structure. ${ }^{10 \mathrm{~g}, 12}$ As a representative example, the molecular structure of $\left[\mathrm{Sn}_{2} \mathrm{~F}_{4}(\mathrm{dmso})_{2}\right]$ shows two types of fluorine atoms (terminal and bridging) but gives rise to only one resonance at $-86.4 \mathrm{ppm}\left(20{ }^{\circ} \mathrm{C}\right)$ in the ${ }^{19} \mathrm{~F}$ NMR spectrum. ${ }^{10 \mathrm{~g}}$ In line with the reported spectra and on the basis of the single resonance positions observed in the ${ }^{19} \mathrm{~F}$ NMR spectra of 3 and 4 , it can be assumed that random intermolecular exchange of the $\mathrm{MF}_{3}^{-}(\mathrm{M}=\mathrm{Ge}, \mathrm{Sn})$ species and rapid exchange of the positions of fluorine atoms play an important role which in turn imply the weakness of $\mathrm{H} \cdots \mathrm{F}$ and Sn $\cdots$ F contacts.

In summary, we have prepared hydrocarbon soluble compounds containing the $\mathrm{GeF}_{3}^{-}$and $\mathrm{SnF}_{3}{ }^{-}$species. While the former shows a monomeric structure, the latter exists as a dimer $\left[\left(\mathrm{SnF}_{3}\right)^{-}\right]_{2}$. Weak hydrogen bonds exist between the two fluorine atoms of each $\mathrm{MF}_{3}{ }^{-}$anion and the $\mathrm{NH}$ protons of the cationic part. Compound 3 represents the first oganometallic compound containing a $\mathrm{GeF}_{3}^{-}$moiety.

Syntheses were carried out under inert gas atmosphere of dinitrogen in oven-dried glassware using standard Schlenk techniques. Other manipulations were accomplished in a dinitrogen filled glovebox. Solvents were purified by MBRAUN solvent purification system MB SPS-800. All chemicals were purchased from Aldrich and used without further purification. Compounds $\mathbf{1}$ and $\mathbf{2}$ were prepared as reported in the literature. ${ }^{4 \mathrm{~d}}{ }^{1} \mathrm{H},{ }^{19} \mathrm{~F}$, and ${ }^{119} \mathrm{Sn}$ NMR spectra in solution were recorded with a Bruker Avance DPX 200 or a Bruker Avance DRX 300 spectrometer, using THF- $d^{8}$ as solvent. Elemental analyses were carried out in the Analytische Labor der Anorganischen Chemie der Universität Göttingen.

To a cooled $\left(-78{ }^{\circ} \mathrm{C}\right)$ solution of $1(500 \mathrm{mg}, 1.44 \mathrm{mmol})$, HF.pyridine $(0.11 \mathrm{~mL}, 4.31 \mathrm{mmol}, 70 \% \mathrm{HF})$ was added very slowly, and the stirring was continued for $30 \mathrm{~min}$ while allowing the temperature to rise gradually. After reaching $0{ }^{\circ} \mathrm{C}$, the solution was subjected to vacuum for a few minutes to remove any amount of unreacted HF, and the solution was warmed to room temperature. Followed by filtration, the solution was partially evaporated and kept at $-5{ }^{\circ} \mathrm{C}$ to yield 3 as a crystalline compound which was separated by decanting the solvent. Storing a solution of 3 in toluene at $0{ }^{\circ} \mathrm{C}$ afforded colorless crystals suitable for X-ray diffraction. (Yield: $74 \%, 0.38 \mathrm{~g}$ ). ${ }^{1} \mathrm{H}$
NMR (THF- $\left.d^{8}, 200 \mathrm{MHz}, 25^{\circ} \mathrm{C}\right): \delta 1.06\left(\mathrm{~s}, 18 \mathrm{H},{ }^{t} \mathrm{Bu}\right), 7.51-$ 7.57 (m, 5H, Ar), 9.22 (br, 2H, NH) ppm; ${ }^{19} \mathrm{~F}$ NMR (THF- $d^{8}$, $282.38 \mathrm{MHz}, 25{ }^{\circ} \mathrm{C}$ ): $\delta-62.98\left(\mathrm{~s}, 3 \mathrm{~F}, \mathrm{GeF}_{3}\right)$ ppm; elemental analysis (\%) calcd for $\mathrm{C}_{15} \mathrm{H}_{25} \mathrm{~F}_{3} \mathrm{GeN}_{2}$ (363.01): C, 49.63, $\mathrm{H}$, 6.94, N, 7.72 Found: C, 49.75, H, 6.96, N, 7.49.

To a cooled $\left(-78{ }^{\circ} \mathrm{C}\right)$ solution of $2(500 \mathrm{mg}, 1.27 \mathrm{mmol})$, HF.pyridine $(0.10 \mathrm{~mL}, 3.81 \mathrm{mmol}, 70 \% \mathrm{HF})$ was added very slowly, and the stirring was continued for $30 \mathrm{~min}$ while allowing the temperature to rise slowly. After reaching $0{ }^{\circ} \mathrm{C}$, the solution was subjected to vacuum for a few minutes to remove any amount of unreacted $\mathrm{HF}$, and the solution was warmed to room temperature. Followed by filtration, the solution was stored at $-5{ }^{\circ} \mathrm{C}$ to afford 4 as a colorless crystalline product which was separated by decantation. Storing a saturated solution of 4 in toluene at $0{ }^{\circ} \mathrm{C}$ afforded single crystals suitable for X-ray diffraction. (Yield: 68\%, 0.35g). ${ }^{1} \mathrm{H}$ NMR (THF- $d^{8}$, $\left.200 \mathrm{MHz}, 25^{\circ} \mathrm{C}\right): \delta 1.05\left(\mathrm{~s}, 18 \mathrm{H},{ }^{t} \mathrm{Bu}\right), 7.41-7.60$ (m, 5H, Ar), $9.81(\mathrm{br}, 2 \mathrm{H}, \mathrm{NH}) \mathrm{ppm}$; ${ }^{19} \mathrm{~F}$ NMR (THF- $d^{8}, 282.38 \mathrm{MHz}, 25$ $\left.{ }^{\circ} \mathrm{C}\right): \delta-81.41\left(\mathrm{~s}, 3 \mathrm{~F}, \mathrm{SnF}_{3}\right) \mathrm{ppm} ;{ }^{119} \mathrm{Sn}$ NMR (THF- $d^{8}, 111$ $\mathrm{MHz}, 25{ }^{\circ} \mathrm{C}$ ): $\delta-531.67 \mathrm{ppm}$. Elemental analysis (\%) calcd for $\mathrm{C}_{15} \mathrm{H}_{25} \mathrm{~F}_{3} \mathrm{~N}_{2} \mathrm{Sn}$ (409.08): C, 44.04, H, 6.16, N, 6.85 Found: C, 44.26, H, 6.24, N, 6.78 .

Molecular structures of compounds 3 and 4 were established by single-crystal X-ray crystallographic studies. X-ray intensity data sets for 3 were collected on a Bruker D8 goniometer with Apex 2 detector and an Incoatec Mo microsource with mirror optics. Data reduction was carried out with SAINT. ${ }^{13}$ Data for 4 were collected at beamline P11 of the new PETRA-III storage ring at DESY in Hamburg. The crystallography endstation at P11 is equipped with a high-precision one-axis goniometer and Pilatus $6 \mathrm{M}$ single photon counting detector. The beam size was adjusted to $200 \mu \mathrm{m}$. Data were collected at a temperature of $120 \mathrm{~K}$ and an X-ray energy of $20 \mathrm{keV}(\lambda=0.6199 \AA)$. In total 540 frames were collected in rotation increments of $0.5^{\circ}$ and an exposure time of $0.25 \mathrm{~s}$ per frame. Data were processed using the XDS program package. ${ }^{14}$ Intensity data for both compounds were corrected for absorption and scaled with SADABS. ${ }^{15}$ Structures were solved by direct methods and refined by full-matrix least-squares methods on $F^{2}$ with the program SHELXL-2013, ${ }^{16}$ utilizing anisotropic displacement parameters for nonhydrogen atoms. Visualization and modeling was done using SHELXLE. ${ }^{17}$

\section{ASSOCIATED CONTENT}

\section{S Supporting Information}

Cif files of 3 and 4 , a table containing crystal structure refinement parameters, and the details of ${ }^{19} \mathrm{~F}$ solid state NMR. This material is available free of charge via the Internet at http://pubs.acs.org.

\section{AUTHOR INFORMATION}

\section{Corresponding Authors}

hroesky@gwdg.de

birger.dittrich@chemie.uni-hamburg.de

Notes

The authors declare no competing financial interest.

\section{ACKNOWLEDGMENTS}

H.W.R. thanks the Deutsche Forschungsgemeinschaft for financial support (RO 224/60-1). Portions of this research were carried out at the PETRA light source at DESY, a member of the Helmholtz Association (HGF). B.D. thanks J. Matussek 
for providing alternative X-ray data for compound 3 and for helpful discussions. We thank Dr. M. John for fruitful suggestions and discussions on NMR spectroscopy.

\section{REFERENCES}

(1) For reviews on silylenes: (a) Haaf, M.; Schmedake, T.; West, R. Acc. Chem. Res. 2000, 33, 704. (b) Hill, N. J.; West, R. J. Organomet. Chem. 2004, 689, 4165. (c) Ottosson, H.; Steel, P. G. Chem.-Eur. J. 2006, 12, 1576. (d) Kira, M. Chem. Commun. 2010, 46, 2893. (e) Asay, M.; Jones, C.; Driess, M. Chem. Rev. 2011, 111, 354. (f) Yao, S.; Xiong, Y.; Driess, M. Organometallics 2011, 30, 1748. (g) Sen, S. S.; Khan, S.; Samuel, P. P.; Roesky, H. W. Chem. Sci. 2012, 3, 659. For reviews on germylenes and stannylenes: (h) Veith, M. Angew. Chem. 1987, 99, 1; Angew. Chem., Int. Ed. Engl. 1987, 26, 1. (i) Neumann, W. P. Chem. Rev. 1991, 91, 311. (j) Dias, H. V. R.; Wang, Z.; Jin, W. Coord. Chem. Rev. 1998, 176, 67-86. (k) Kühl, O. Coord. Chem. Rev. 2004, 248, 411. (1) Saur, I.; Alonso, S. G.; Barrau, J. Appl. Organomet. Chem. 2005, 19, 414. (m) Leung, W.-P.; Kan, K.-W.; Chong, K.-H. Coord. Chem. Rev. 2007, 251, 2253. (n) Nagendran, S.; Roesky, H. W. Organometallics 2008, 27, 457. (o) Tokitoh, N.; Okazaki, R. Coord. Chem. Rev. 2000, $210,251$.

(2) Murphy, E. F.; Murugavel, R.; Roesky, H. W. Chem. Rev. 1997, 97, 3425.

(3) (a) Rivière, P.; Satgé, J.; Castel, A.; Normant, H. C. R. Acad. Sci. Paris. 1976, 282, 971. (b) Ding, Y.; Hao, H.; Roesky, H. W.; Noltemeyer, M.; Schmidt, H.-G. Organometallics 2001, 20, 4806.

(4) (a) Chorley, R. W.; Ellis, D.; Hitchcock, P. B.; Lappert, M. F. Bull. Soc. Chim. Fr. 1993, 129, 599. (b) Jana, A.; Roesky, H. W.; Schulzke, C.; Döring, A.; Beck, T.; Pal, A.; Herbst-Irmer, R. Inorg. Chem. 2009, 48, 193. (c) Jana, A.; Roesky, H. W.; Schulzke, C.; Samuel, P. P. Organometallics 2010, 29, 4837. (d) Samuel, P. P.; Singh, A. P.; Sarish, S. P.; Matussek, J.; Objartel, I.; Roesky, H. W.; Stalke, D. Inorg. Chem. 2013, 52, 1544.

(5) Jana, A.; Sarish, S. P.; Roesky, H. W.; Leusser, D.; Objartel, I.; Stalke, D. Chem. Commun. 2011, 47, 5434.

(6) (a) Martin, R. W.; Merer, A. J. Can. J. Phys. 1973, 51, 125. (b) van der Kerk, S. M. Polyhedron 1983, 2, 509. (c) Takeo, H.; Curl, R. F.; Wilson, P. W. J. Mol. Spectrosc. 1971, 38, 464. (d) Caunt, A. D.; Mackle, H.; Sutton, L. E. Trans. Faraday Soc. 1951, 47, 943.

(7) Harland, P. W.; Cradock, S.; Thynne, J. C. J. Int. J. Mass Spectrom. Ion Phys. 1972/73, 10, 169.

(8) Li, Q.; Li, G.; Xu, W.; Xie, Y.; Schaefer, H. F., III J. Chem. Phys. 1999, 111, 7945.

(9) Bjarnason, E. H.; Omarsson, F. H.; Hoshino, M.; Tanaka, H.; Brunger, M. J.; Limao-Vieira, P.; Ingolfsson, O. Int. J. Mass Spectrom. 2013, 339, 45 .

(10) (a) Bergerhoff, G.; Goost, L.; Schultke-Rhonhof, E. Acta Crystallogr. 1968, B24, 803. (b) Bergerhoff, G.; Goost, L. Acta Crystallogr. 1973, B29, 632. (c) Kaučič, V.; Leban, I.; GašperšičŠkander, S.; Gantar, D.; Rahten, A. Acta Crystallogr. 1988, C44, 1329. (d) Abrahams, I. Acta Crystallogr. 1995, C51, 345. (e) Kokunov, Y. V.; Gorbunova, Y. E.; Petrov, V. N.; Gustyakova, M. P.; Buslaev, Y. A. Dokl. Akad. Nauk SSSR 1989, 307, 1126. (f) Boufas, S.; Merazig, H.; Moliterni, A. G.; Altomare, A. Acta Crystallogr. 2007, C63, m315. (g) Gurnani, C.; Hector, A. L.; Jager, E.; Levason, W.; Pugh, D.; Reid, G. Dalton Trans. 2013, 42, 8364.

(11) Singh, A. P.; Roesky, H. W.; Carl, E.; Stalke, D.; Demers, J. -P.; Lange, A. J. Am. Chem. Soc. 2012, 134, 4998.

(12) (a) Benjamin, S. L.; Burt, J.; Levason, W.; Reid, G.; Webster, M. J. Fluor. Chem. 2012, 135, 108. (b) Levason, W.; Light, M. E.; Maheshwari, S.; Reid, G.; Zhang, W. Dalton Trans. 2011, 40, 5291.

(13) SAINT, version 7.68A; Bruker APEX, version 2011.9; Bruker

AXS: Madison, WI, 2011.

(14) Kabsch, W. Acta Crystallogr. 2010, D66, 125.

(15) Sheldrick, G. M. SADABS; University of Göttingen: Göttingen, Germany, 2009.

(16) Sheldrick, G. M. Acta Crystallogr. 2008, A64, 112.
(17) Hübschle, C.; Sheldrick, G. M.; Dittrich, B. J. Appl. Crystallogr. 2011, 44, 1281. 